\title{
AN INDUCTIVE ANALYSIS OF TRADE PARAMETERS APPLYING LOGISTICAL FUNCTIONS
}

Framarz Byramjee, Indiana University of Pennsylvania, Indiana, Pennsylvania, U.S.A. Pankaj Chaudhary, North Carolina A\&T State University, Greensboro, North Carolina, U.S.A. Parimal Bhagat, Indiana University of Pennsylvania, Indiana, Pennsylvania, U.S.A. Jill Baumgardner, Indiana University of Pennsylvania, Indiana, Pennsylvania, U.S.A. Kevin Lhota, Indiana University of Pennsylvania, Indiana, Pennsylvania, U.S.A.

\section{dx.doi.org/10.18374/IJBR-21-1.6}

\begin{abstract}
This paper implements an Inductive-Statistical method of scientific inquiry toward formulating the discourse for trade deficit and surplus reasoning within the global commerce scape. The research design extends a prior nomologically modeled framework of transportation effectiveness by applying reliable secondary data for nations' logistics performance parameters mined from the World Bank Database and nations' exports and imports metrics mined from the International Monetary Fund Database to build the deficit and surplus dichotomy reflecting balance of trade criterion. The analytical structuring tests for the concerted logistical variables' relevant effects by empirically examining several relationships among those constituent sets of explanans influencing the present explananda, patterning inductive research modularity. The contributory and classificatory abilities of these logistical functions, as global business marketing and operations covariates geared toward respectively explaining/predicting and categorizing nations' trade-deficit/surplus situations, are inductively examined by applying pertinent multivariate techniques for analyzing the data and interpreting the results for their suited statistical significances and substantive implications.
\end{abstract}

Keywords: Logistics Functions, Trade, Imports, Exports, Surplus, Deficit, Prediction, Classification 